Linha D’Água (Online), São Paulo, v. 33, n. 1, p. 129-149, jan.-abr. 2020

\title{
O FENÔMENO DA NEOLOGIA LEXICAL NAS ELEIÇÕES DE 2018
}

\section{THE LEXICAL NEOLOGY PHENOMENON IN THE 2018 ELECTIONS}

\author{
Rove Chishman*
}

Universidade do Vale do Rio dos Sinos, São Leopoldo, RS, Brasil

Aline $\mathcal{X}$ ardes dos Santos ${ }^{* *}$

Universidade do Vale do Rio dos Sinos, São Leopoldo, RS, Brasil

Paola Martins ***k $^{* * 2}$

Universidade do Vale do Rio dos Sinos, São Leopoldo, RS, Brasil

\begin{abstract}
Resumo: Este trabalho apresenta um estudo do fenômeno da neologia lexical através da análise de neologismos produzidos no períado das eleiçōes realizadas no Brasil no ano de 2018. Para o delineamento de nossa metodologia, utilizamos os preceitos estabelecidos pelo projeto Observatório de Neologia do Português (ONP), sob a coordenacção de Margarita Correia, assim como a sistematização apresentada por Correia e Almeida (2012). Com base nos dados levantados, foram detectados 73 neologismos, sendo 24 formados por derivacã̃o (33\% do total de palavras novas), 21 por processos deformacionais (28\% dos casos), nove por lexicalizaçã̃o, sete por extensão semântica, sete por composiç̃ão e cinco por empréstimos. Os casos de derivaç̃ão sufixal servem para corroborar ser a sufixaçã̃o o mecanismo mais rico e diversificado da língua portuguesa. É nessa classe que encontramos os casos de neologia denominativa, ainda que em sua maioria restritos a nomes de políicicos ou a partidos, e não a objetos ou conceitos. Já os neologismos criados por processos deformacionais se destacam por indicarem, em sua grande maioria, casos de neologia estilistica, evidenciando a intenç̃õo dos usuários em criar tais termos como forma de expressar sua opinião ou sua repulsa a um ou outro candidato.
\end{abstract}

Palavras-chave: neologia; neologismos; inovaç̦ão lexical; empréstimos.

Abstract: This paper presents a study of the phenomenon of lexical neology through the analysis of neologisms produced in the period of the elections held in Brazil in 2018. In order to delineate our methodology, we used the precepts established by the Portuguese Neology Observatory (ONP) project. coordinated by Margarita Correia, as well as the systematization presented by Correia

* Professora doutora da Universidade do Vale do Rio dos Sinos - UNISINOS, São Leopoldo, RS, Brasil; Bolsista de Produtividade do CNPq; rove@unisinos.br

** Doutora em Linguística Aplicada pela Universidade do Vale do Rio dos Sinos - UNISINOS, São Leopoldo, RS, Brasil; aline.nardes@gmail.com

*** Graduanda em Letras da Universidade do Vale do Rio dos Sinos - UNISINOS, São Leopoldo, RS, Brasil; monamartins@icloud.com

http://dx.doi.org/10.11606/issn.2236-4242.v33ilp129-149

Todo conteúdo da Linha D'Água está sob Licença Creative Commons Attribution-NonCommercial 4.0 International License 
Linha D'Água (Online), São Paulo, v. 33, n. 1, p. 129-149, jan.-abr. 2020

\& Almeida (2012). Based on the data collected, 73 neologisms were detected, 24 formed by derivation (33\% of total new words), 21 by deformational processes (28\% of cases), nine by lexicalization, seven by semantic extension, seven by composition and five for loanswords. The cases with suffixes serve to corroborate that suffix derivation is the richest and most diversified mechanism of the Brazilian Portuguese language. It is in this class that we find cases of denominational neology, though mostly restricted to the names of politicians or political parties rather than objects or concepts. On the other hand, the neologisms created by deformational processes stand out for indicating, in their majority, cases of stylistic neology, evidencing the intention of the users to create such terms as a way to express their opinion or their repulsion to one or another candidate.

Keywords: Neology; Neologisms; Lexical Innovation; Loanwords.

\section{Introdução}

Este trabalho apresenta um estudo do fenômeno da neologia lexical através da análise de neologismos produzidos no período das eleições realizadas no ano de 2018. Importa registrar que tal análise vale-se dos resultados obtidos em uma atividade de ensino realizada como parte do programa da disciplina Fundamentos de Morfologia do curso de Letras da Universidade do Vale do Rio dos Sinos (UNISINOS). Como parte do estudo sobre neologia, os alunos foram desafiados a construir um glossário como forma de aplicar os conceitos de morfologia estudados ao longo do curso. Os detalhes da metodologia empregada serão apresentados na sequência, assim como os do recurso lexicográfico produzido.

Essa atividade foi planejada, tendo-se em vista dois propósitos: (i) o de fazer com que os alunos experienciassem o passo a passo da pesquisa linguística, incluindo não apenas o estudo do fenômeno, mas também a coleta e análise dos dados, e (ii) o de evidenciar que os fenômenos estudados fazem parte da língua em uso, e que o léxico, em especial, tem o papel de materializar a realidade. No que diz respeito ao recorte escolhido, vemos a criação de novas palavras como a expressão viva dos acontecimentos fervorosos e tensos que marcaram as eleições federais de 2018.

Além do objetivo geral já explicitado, o trabalho tem como propósito relatar a etapa de levantamento dos neologismos, assim como a de classificação, organização e estudo dos casos identificados.

Para alcançar tais objetivos, organizamos o artigo em seções que tratam dos seguintes tópicos: (i) os procedimentos metodológicos, (ii) o conceito de neologia

CHISHMAN, R. L. O., SANTOS, A. N., MARTINS, P. 0 fenômeno da neologia lexical nas eleiç̃ões de 2018 
Linha D’Água (Online), São Paulo, v. 33, n. 1, p. 129-149, jan.-abr. 2020

e (iii) a descrição e a análise dos dados. A discussão mais ampla é apresentada na seção de considerações finais.

\section{Procedimentos metodológicos}

Inspiramo-nos nos preceitos estabelecidos pelo projeto Observatório de Neologia do Português $(\mathrm{ONP})^{1}$, realizado pela equipe do Centro de Estudos em Léxico e Terminologia da Universidade de Lisboa, sob a coordenação de Margarita Correia, para o delineamento de nossa metodologia. Valemo-nos também da sistematização apresentada por Alves $(2011,2016)$ e por Correia e Almeida (2012), especialmente por conta dos ajustes sugeridos para o levantamento de neologismos no âmbito do português brasileiro, assim como dos critérios propostos pela professora Maria Teresa Cabré, também integrante do ONP.

A criação de um observatório, segundo Cabré (2003), pode ser descrita em três fases:

(i) Desenho e organização, compreendendo seleção do corpus, definição de critérios para detecção de neologismos e redação de protocolos para os investigadores;

(ii) Coleta e análise dos neologismos a partir dos critérios predefinidos;

(iii) Exploração dos dados, o que, em essência, corresponde à sua difusão.

No âmbito de nosso projeto, os procedimentos metodológicos previram as seguintes atividades:

(i) Constituição do corpus de extração:

Escolhemos como corpus a web, em especial sites jornalísticos de natureza política e mídias sociais, com registros no período eleitoral e pós-eleitoral. Como justificativa para o uso de ambientes virtuais para o propósito desta pesquisa, recorremos a Rajagopalan (2003), que afirma que "estamos diante de uma

1 No que se refere ao português brasileiro, cita-se o projeto TermNeo - Observatório de Neologismos do Português Brasileiro Contemporâneo, sob coordenação da professora leda Alves (USP).

CHISHMAN, R. L. O., SANTOS, A. N., MARTINS, P. 0 fenômeno da neologia lexical nas eleições de 2018 
Linha D’Água (Online), São Paulo, v. 33, n. 1, p. 129-149, jan.-abr. 2020

língua em construção, uma língua sendo moldada de acordo com as necessidades e conveniências que vão surgindo, movida e enriquecida pela novidade e engenhosidade dos milhões de usuários" (RAJAGOPALAN, 2003, p. 27). No que se refere ao recorte deste trabalho, fica evidente que o ambiente virtual serve como o principal canal de comunicação para compartilhamento de opiniões e críticas. Para compilação do corpus jornalístico, foi utilizada a ferramenta de criação de corpora do Sketch Engine, que extrai textos da web a partir da inserção de palavras-semente (seeds). Nesse caso, foram inseridos os termos "Eleições 2018", "política", "Geraldo Alckmin", "Fernando Haddad", "Ciro Gomes", "Marina Silva" e "Jair Bolsonaro". Após a coleta automática de textos que continham duas ou mais seeds, totalizando 267,745 tokens, o corpus foi baixado e convertido para o formato .doc, de modo a facilitar as buscas de exemplos pelos alunos. Tal processo de pesquisa no corpus complementou a busca manual de possíveis neologismos e seus exemplos em redes sociais, a qual foi realizada pelos estudantes como tarefa extraclasse. ${ }^{2}$

(ii) Definição do corpus de exclusão:

A ideia de incluir essa atividade na metodologia decorre da escolha pelo critério lexicográfico, considerado o mais seguro dentre as quatro formas de detecção de neologismos. De posse da lista de possíveis neologismos, consultamos três dicionários como corpus de exclusão, os quais serviram "como referência para a determinação do caráter neológico" dos itens lexicais encontrados (ALVES, 2011, p. 130). Os dicionários consultados foram: Michaelis Dicionário Brasileiro da Língua Portuguesa (2009), Grande Dicionário Houaiss Beta da Língua Portuguesa (2012), e Caldas Aulete (2015), todos em versão digital - formato também utilizado no estudo de Alves (2011) para investigar candidatos a neologismos.

(iii) Identificação dos possíveis neologismos:

2 Importante salientar que, em virtude do caráter didático da atividade, o ponto de partida para a coleta de itens lexicais foi a busca dos estudantes, servindo os corpora de estudo e de exclusão como forma de atestar os itens por eles pesquisados. Desse modo, vislumbra-se como etapa futura a coleta semiautomática de neologismos a partir do processamento de palavraschave do corpus, com vistas a complementar as descrições já realizadas.

CHISHMAN, R. L. O., SANTOS, A. N., MARTINS, P. 0 fenômeno da neologia lexical nas eleições de 2018 
Linha D’Água (Online), São Paulo, v. 33, n. 1, p. 129-149, jan.-abr. 2020

A identificação dos neologismos se deu pelo método manual. Optamos por não usar o método automático ou semiautomático, como procede o projeto OLP, por duas razões: primeiro, pela dificuldade de os softwares de detecção automática identificarem os casos de neologismos semânticos e, segundo, pela complexidade de trabalho que geraria para o grupo de alunos, na medida em que teriam de pré-processar o corpus para ser submetido à ferramenta ${ }^{3}$, o que não seria viável pelo tempo reservado para a atividade.

(iv) Descrição e análise dos neologismos detectados:

Tendo verificado que os candidatos a neologismos não constavam nos corpora de exclusão, os alunos, divididos em grupos, passaram à sua classificação. Os termos encontrados foram classificados conforme a tipologia de Correia \& Almeida (2012), que institui seis categorias, sendo elas: composição, derivação, processos deformacionais, lexicalização, extensão semântica e empréstimos e hibridismos. No caso da última categoria, optou-se pela nomenclatura de Rocha (2003), uma vez que melhor se aplica às necessidades do trabalho. Cada categoria é ainda constituída de diferentes subtipos, dentre os quais foram organizados os neologismos.

(v) Coleta de exemplos de uso:

Os exemplos de uso do neologismo fizeram parte da estrutura do verbete no glossário, conforme ficha apresentada a seguir. Também foi feita a análise da frequência como critério para atestar se a unidade é ou não neológica.

(vi) Definição de ficha para registro dos neologismos:

Sobre as informações a constar na ficha, importa esclarecer que priorizamos o detalhamento do processo de construção evidenciado, já que o principal objetivo da atividade era aplicar os conceitos estudados ao longo do semestre. Outros critérios de classificação, como o tipo de novidade ou a própria distinção entre neologia denominativa e neologia estilística, serão empregados na análise dos dados. Nesse sentido, adotamos a seguinte estrutura4:

3 Para o Português brasileiro, há disponível a ferramenta SENTER (2006), desenvolvida pelo pesquisador Tiago Pardo, do Núcleo Interinstitucional de Linguística Aplicada (NILC), da USP de São Carlos. O software está disponível para download em: http://www.nilc.icmc.usp.br/ nilc/index.php/tools-and-resources.

4 Além das indicações sobre as informações que deveriam constar na ficha, o template

CHISHMAN, R. L. O., SANTOS, A. N., MARTINS, P. 0 fenômeno da neologia lexical nas eleiç̃ões de 2018 
Linha D’Água (Online), São Paulo, v. 33, n. 1, p. 129-149, jan.-abr. 2020
a. Forma lematizada do neologismo;
b. Processo morfológico;
c. Características discursivas: de 20 a 40 palavras;
d. Exemplo, fonte, data.

(vii) Edição do glossário em plataforma web:

O glossário, intitulado Glossário Neopolitiquês (CHISHMAN, 2018), foi desenvolvido em forma de site por meio da plataforma Wix e está publicado na URL https://gneo2018.wixsite.com/gneo2018.

\section{0 conceito de neologia}

Denominamos de neologia o processo de criação de novas palavras. Como processo, a neologia pode ser concebida como a capacidade natural de renovação do léxico de uma língua pela formação de novos itens lexicais. A neologia, nesse sentido, vem a se ocupar da observação, registro, descrição e análise dos neologismos que vão surgindo na língua. Assumem centralidade questionamentos como "Por que, quando e como se formam novas palavras?" ou "Através de que mecanismos linguísticos ocorre a formação de palavras novas?”

Louis Guilbert (1975, p. 31), referência nos estudos sobre neologia, definiu criação lexical como "a possibilidade de criação de novas unidades lexicais em virtude de regras de produção do interior do sistema lexical"'. Carvalho (2006), a partir dessa ideia, considera que a criação lexical conduz o pesquisador à análise do contexto social do qual emergiram as novas unidades, sendo inseparável o estudo da criação lexical e a análise do contexto sócio-histórico em que se criaram as novas palavras.

Os neologismos, por sua vez, são o resultado, o produto, que, depois de passar pelo processo, pertence a uma determinada tipologia. A esse respeito, Cabré (2010, p. 18) afirma que o trabalho com a neologia implica algumas questões polêmicas, apesar de o conceito estar há algum tempo relativamente estabilizado. A autora

\footnotetext{
também contou com orientações sobre a formatação, tais como tamanho de fonte, espaçamento e uso de negrito e itálico.

5 Tradução livre de "La néologie lexicale se définit par la possibilité de création de nouvelles unités lexicales, en vertu de règles de producion incluses dans le système lexical".
}

CHISHMAN, R. L. O., SANTOS, A. N., MARTINS, P. 0 fenômeno da neologia lexical nas eleições de 2018 
Linha D’Água (Online), São Paulo, v. 33, n. 1, p. 129-149, jan.-abr. 2020

salienta que o rótulo de neologismo pode ser problemático porque, por definição, a neologia é uma condição sempre diacrônica: aquilo que hoje é neológico pode deixar de ser quando se dissemina seu uso. Isso implica considerar que uma dada unidade lexical apenas pode ser considerada neológica em relação à época em que surge e ao estágio imediatamente anterior da língua, ao significado que é atualizado num dado contexto e ao registro linguístico em que ocorre.

Sem deixar de reconhecer a problemática conceitual, Cabré (2010, p. 18) propõe quatro critérios para detectar neologismos. São eles: a) critérios diacrônicos, considerando unidades que apareceram recentemente; b) critérios gramaticais, referindo-se à instabilidade formal das unidades; c) critérios psicológicos, envolvendo o sentimento de novidade; e d) critérios lexicográficos, referindo-se à ausência das unidades nos dicionários.

Pela necessidade de estabelecimento de critérios mais objetivos, muitos grupos de pesquisa que se ocupam do estudo da neologia, dentre eles o projeto $\mathrm{Ob}$ servatório de Neologia do Português (ONP), têm dado ênfase ao critério lexicográfico, considerando como neológica uma unidade não registrada nos dicionários representativos do estado da língua em questão. Decorre da adoção desse critério a noção de corpus de exclusão.

Quanto ao tipo de neologia, Correia e Almeida (2012, p. 18) fazem menção a duas categorias: a neologia denominativa, que é resultante da necessidade de nomear novas realidades, e a neologia estilística, a qual corresponde à procura de uma maior expressividade do discurso. Haveria também um terceiro tipo, denominado de neologia de língua, correspondendo a unidades lexicais que resultam apenas da atualização de regras de formação derivacionais, não despertando qualquer sentimento de novidade no falante. São exemplos dessa terceira categoria os advérbios em -mente (calmamente, fortuitamente).

Ainda que tal tipologia não apresente detalhes quanto aos mecanismos de que os léxicos dispõem para incorporar palavras novas, a distinção entre neologia denominativa e neologia estilística é central em nosso estudo, à medida que nos ajuda a compreender o número expressivo de neologismos com efeito pejorativo ou ofensivo coletados. 
Linha D’Água (Online), São Paulo, v. 33, n. 1, p. 129-149, jan.-abr. 2020

Correia e Almeida (2012, p. 33) apontam como sendo basicamente três os processos disponíveis para a inovação lexical. São eles: a) a construção de palavras, recorrendo a regras da própria língua; b) a atribuição de novos significados a palavras já existentes e c) a importação de palavras de outras línguas.

O primeiro processo, correspondendo à construção de palavras dentro do sistema do português, engloba quatro grandes categorias: a derivação, a composição, os processos deformacionais e a lexicalização de estruturas.

Incluem-se na derivação processos de natureza distinta: temos a derivação afixal, que é o processo de construção de palavras através do qual se obtém um derivado pela junção de um afixo a um radical, e a derivação não afixal, também chamada de conversão, em que não há a intervenção de quaisquer afixos, ocorrendo apenas uma mudança categorial do radical que é alvo de derivação.

Considerado o processo de inovação lexical o mais produtivo e o mais regular, a derivação afixal pode ser vista como um processo tipicamente binário. Isso significa que em cada processo derivacional estão envolvidos uma base ou um radical derivacional e um afixo. São três os subtipos de derivação afixal: sufixação (como bolsonarista), prefixação (como antibolsonarismo) e parassíntese (como esfakear).

A derivação não afixal ou conversão refere-se aos casos em que não ocorre distinção formal entre base e derivado. Denominada pela gramática tradicional de derivação imprópria, a conversão ocorre quando uma determinada categoria morfossintática muda a sua categoria com a correspondente mudança de significado e de padrão flexional.

A segunda categoria do grupo de palavras criadas a partir das regras do próprio sistema linguístico é a composição. Considerado um processo menos previsível do que a derivação, a composição reúne pelo menos duas unidades de significado lexical, autônomas ou não autônomas, previamente existentes na língua, que se unem para formar uma nova unidade lexical. Existem cinco tipos de composição: composição morfológica, composição morfossintática, recomposição, justaposição e aglutinação.

A terceira categoria desse primeiro grupo é denominada por Correia e Almeida (2012) de processos deformacionais de construção de palavras, os quais abrangem as amálgamas (também conhecidas como palavras-valise ou blends), os casos de truncação, as siglas e os acrônimos. Constituídas como partes de outras 
Linha D’Água (Online), São Paulo, v. 33, n. 1, p. 129-149, jan.-abr. 2020

palavras, as amálgamas, em nosso estudo, ocorreram de forma muito expressiva. Bolsomito, brazuela e tranquiliddad são alguns dos muitos casos. Alcirina (Alckmin + Ciro + Marina) valeria como exemplo de neologismo em forma de acrônimo. Casos de truncação, como portuga, ou siglagem, como $O N U$, não foram encontrados no levantamento feito.

Por fim, a quarta categoria do primeiro tipo de processo refere-se aos casos de lexicalização de estruturas. Correia e Almeida (2012) apresentam os casos de formas flexionadas, compostos sintagmáticos e unidades discursivas como exemplos de lexicalização.

O segundo processo, abarcando os casos em que ocorre a atribuição de novos significados a palavras já existentes, recebe por Correia e Almeida (2012, p. 62) a denominação de extensão semântica. Destacam-se aqui os processos semânticos geradores de polissemia, assim como mecanismos aplicados de forma pontual, como é o caso das metáforas e metonímias, compreendidas pelas autoras não como meros recursos estilísticos e discursivos, mas como recursos cognitivos facilitadores da conceptualização da realidade.

O terceiro mecanismo compreende o fenômeno da importação de palavras. Correia e Almeida (2012, p. 68-74) chamam a atenção para o fato de que, dos três processos disponíveis, a importação de palavras é o processo cujos resultados provocam um impacto significativo. Isso ocorre porque as unidades importadas, por serem produzidas em sistemas linguísticos distintos do nosso, têm características formais que tornam o seu uso difícil, especialmente para os falantes que não têm contato com a língua-fonte dessas palavras.

Vale destacar também o esclarecimento feito quanto ao uso do termo $\mathrm{em}$ préstimo quando se trata de palavras importadas. Longe de se considerar o termo empréstimo como sem ambiguidade, as autoras fazem menção à distinção entre estrangeirismo e empréstimo estabelecida pela gramática tradicional, que se justificaria para diferenciar os casos em que a palavra importada conserva as características formais de seus sistema de origem dos casos em que há adaptação à língua de acolhimento. Ressaltam, por fim, ser discutível a manutenção dos dois conceitos, haja vista as pesquisas mais recentes que demonstram que toda e qualquer palavra 
Linha D’Água (Online), São Paulo, v. 33, n. 1, p. 129-149, jan.-abr. 2020

que entra num sistema linguístico acaba passando por adaptação, ainda que apenas no nível fonológico.

\section{Descrição e análise dos dados}

Com base nos dados levantados e corroborados respectivamente por intermédio dos corpora de pesquisa e de exclusão, foram detectados 73 neologismos formados a partir de variados processos de inovação lexical.

O gráfico a seguir apresenta os percentuais atribuídos a cada classe supracitada:

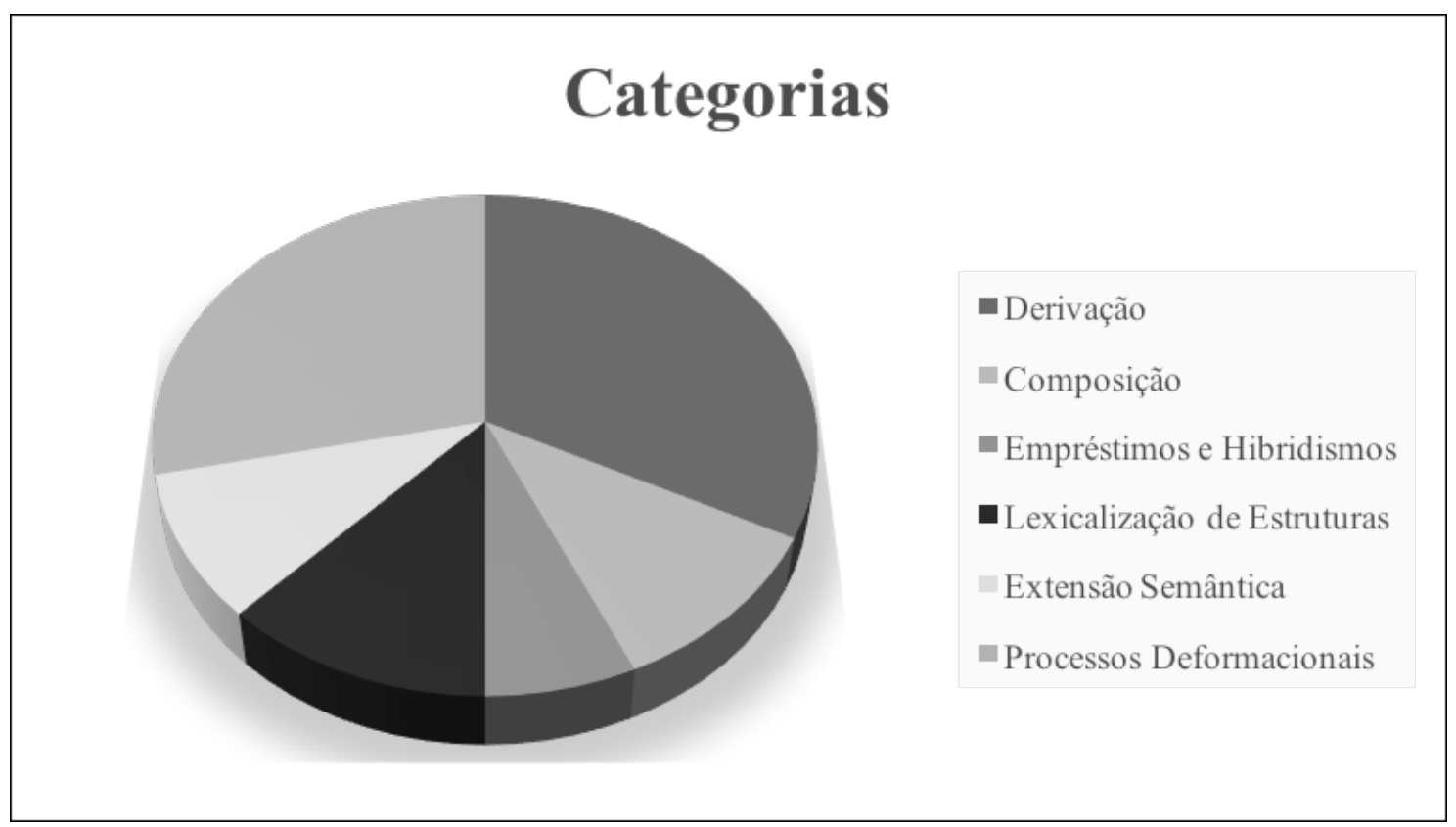

Gráfico 1: Porcentagem atribuída a cada categoria

Fonte: Elaborado pelas autoras.

\subsection{Derivação}

Os resultados encontrados corroboram os dizeres dos autores, uma vez que foram identificados 24 neologismos formados por derivação, sendo essa categoria a representante de cerca de $33 \%$ dos termos e a maior porcentagem aferida no gráfico apresentado anteriormente.

CHISHMAN, R. L. O., SANTOS, A. N., MARTINS, P. 0 fenômeno da neologia lexical nas eleiç̃ões de 2018 
Linha D’Água (Online), São Paulo, v. 33, n. 1, p. 129-149, jan.-abr. 2020

Os casos se distribuem em diferentes processos de derivação configurados como subcategorias, sendo elas: prefixal, sufixal, conversiva ou derivação imprópria, regressiva e parassintética.

\section{Prefixal}

Foi identificado apenas um neologismo formado por derivação prefixal, o substantivo antibolsonarismo, em que foi acrescido o prefixo anti-, originário do grego e detentor de valor semântico de oposição e contrariedade.

\section{Sufixal}

Em nosso estudo, foram encontrados 22 neologismos formados por derivação sufixal, através da adição de 11 elementos sufixais diferentes, elencados no quadro abaixo com a sua respectiva frequência:

Quadro 2: Sufixos

\begin{tabular}{|c|c|c|c|}
\hline$-\operatorname{aço~(1)~}$ & - ândia (1) & - ete (1) & - ismo (4) \\
\hline - ada (2) & $-\operatorname{ar}(2)$ & - gate (1) & - ista (6) \\
\hline - alha (1) & - ção (1) & - iana (2) & \\
\hline
\end{tabular}

Fonte: Elaborado pelas autoras.

Cada um desses sufixos possui papel de adjetivação, de formação de substantivos ou de formação de verbos.

(i) $\mathrm{AÇO}-\mathrm{O}$ sufixo - aço aparece frequentemente como marca de exagero, pois é utilizado para a "formação de aumentativos de substantivos"(SANDMANN, 1987, p. 58). Além disso, tal sufixo pode ser atribuído à ideia de golpe, toque forte, como em buzinaço e joelhaço, ou ainda como manifestação ruidosa, no caso de panelaço (SANDMANN, 1987). O único termo formado com este sufixo foi lulaço, o qual se encaixa na última significação citada. 
Linha D’Água (Online), São Paulo, v. 33, n. 1, p. 129-149, jan.-abr. 2020

(ii) $\mathrm{ADO}(\mathrm{A})-\mathrm{O}$ sufixo -ado(a), quando relacionado a substantivos, adjetivos e nomes, carrega o sentido de coletivo, de conexão compartilhada por um grupo. Em outras situações, esse sufixo pode também atuar como formador de adjetivos, caso em que carrega a ideia de posse. Neste trabalho, o sufixo -ado(a) ocorreu em duas palavras: petezada e petralhada. Conforme explicado no próprio Glossário Neopolitiquês (CHISHMAN, 2018), o primeiro é junção da sigla PT (Partido dos Trabalhadores) ao sufixo com auxílio de $-z$, consoante de ligação. O segundo é também uma referência ao Partido dos Trabalhadores, pois conecta petralha e -ada. Em ambos os casos, os termos apareceram conectados à ideia de coletivo.

(iii) ALHA - Conforme Cunha e Cintra apresentam em sua obra Breve Gramática do Português Contemporâneo (1985), o sufixo -alha carrega um valor coletivo e também pejorativo, do qual é exemplo clássico o termo gentalha. Em nossa pesquisa, encontrou-se o termo direitalha, que, tal qual gentalha, se trata da adição do sufixo à palavra direita, dotando então o substantivo de sentido pejorativo. Tal termo é utilizado para se referir às pessoas que apoiam ideologias direitistas.

(iv) AR-O sufixo - ar se configura como responsável pela formação de novos verbos na língua portuguesa, uma vez que, quando adicionado a um substantivo ou adjetivo, transforma esse em verbo na forma infinitiva (CUNHA; CINTRA, 1985). Cirar e sobralizar foram os neologismos formados a partir da junção do sufixo supracitado aos substantivos próprios Ciro e Sobral. No contexto das eleições de 2018, o primeiro termo diz respeito à participação e/ou realização de campanhas em apoio ao candidato Ciro Gomes. Já o segundo termo, criado pelo próprio Ciro Gomes, muda o nome da cidade do estado do Ceará e faz referência aos resultados obtidos no Índice de Desenvolvimento da Educação Básica (IDEB) na época em que o candidato exercia seu mandato.

(v) ÇÃO - Segundo Cunha e Cintra (1985), o sufixo -ção forma substantivos a partir de bases verbais. É exatamente esse o caso do único termo presente em nossa pesquisa, conforme recorte autoexplicativo do glossário: 
Linha D'Água (Online), São Paulo, v. 33, n. 1, p. 129-149, jan.-abr. 2020

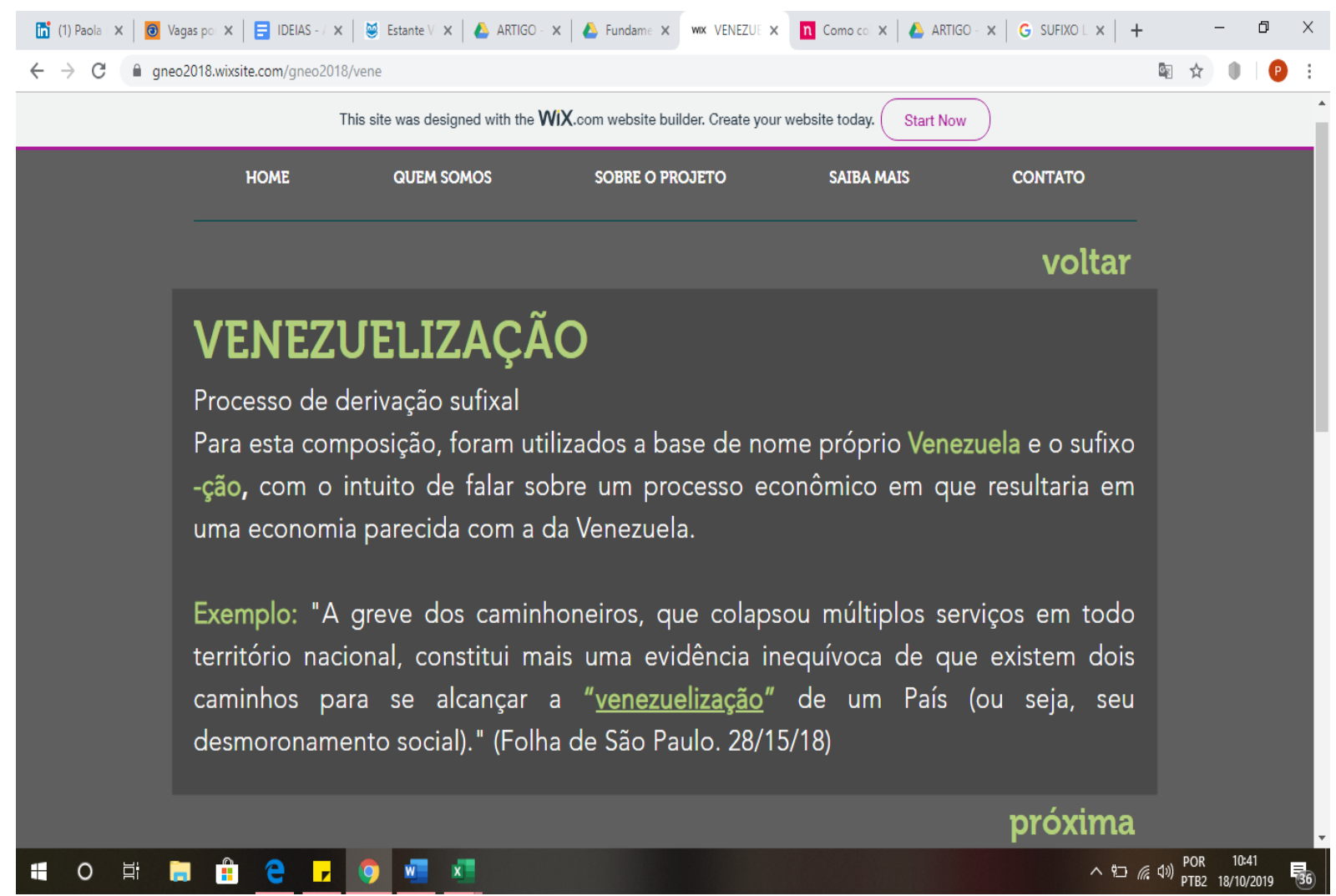

Figura 1: Verbete Venezuelização

Fonte: Glossário Neopolitiquês (CHISHMAN, 2018).

(vi) ETE - O processo de utilização desse sufixo se iniciou a partir da palavra tiete e pode aparecer tanto no sentido afetivo quanto no irônico. Os termos formados a partir da adição desse sufixo são geralmente usados para se referir a admiradores ou fãs de uma pessoa em específico, tanto que são formados pelo substantivo próprio + -ete. É esse o caso de daciolete, termo que faz referência aos admiradores de Cabo Daciolo.

(vii) GATE - Gate se caracteriza como um sufixo emprestado (SANDMANN, 1987), pois é originário da língua inglesa e possui registros anteriores em casos de escândalos da esfera política estadunidense. Apenas um termo foi encontrado, conforme figura abaixo:

CHISHMAN, R. L. O., SANTOS, A. N., MARTINS, P. 0 fenômeno da neologia lexical nas eleiç̃ões de 2018 
Linha D'Água (Online), São Paulo, v. 33, n. 1, p. 129-149, jan.-abr. 2020

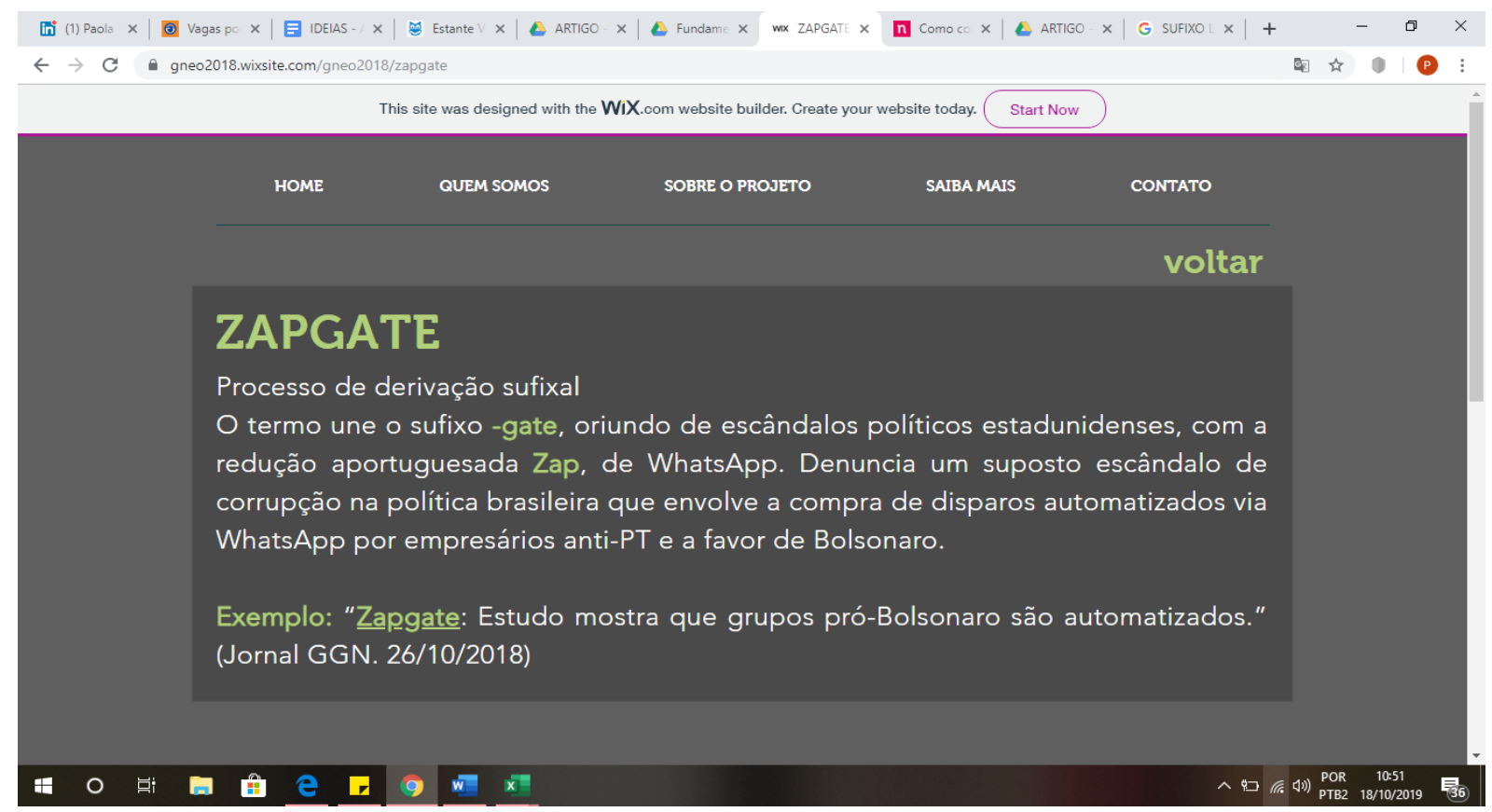

Figura 2: Verbete Zapgate

Fonte: Glossário Neopolitiquês (CHISHMAN, 2018).

(viii) IANO (A) - Conforme Cunha e Cintra (1985), -iano é alomorfe do sufixo -ano, o qual aponta diferentes significados, podendo ser usado como: a) referência a origem, como em romano; b) indicação de que alguém é simpatizante ou partidário de pessoa ou grupo, como em luterano; ou c) apresentação de uma ideia de semelhança ou comparação, como em camoniano. É dentro do segundo significado citado que os dois neologismos encontrados, alckiminiana e bolsonariano, se enquadram. A junção do sufixo aos substantivos próprios Alckmin e Bolsonaro indica uma pessoa que compactua com a ideologia dos candidatos.

(ix) ISMO - O sufixo -ismo foi o segundo mais produtivo na porcentagem de sufixos utilizados, representando 18\% do valor do gráfico. Entre outras possibilidades, esse sufixo é comumente utilizado para denominar doutrinas ou sistemas, conforme Cunha e Cintra (1985), o que não foi diferente no caso dos neologismos presentes neste trabalho. Os termos encontrados foram: $c i-$ rismo, daciolismo, lulismo e coitadismo. Os três primeiros foram formados a partir da junção de nomes próprios, respectivamente Ciro, Daciolo e Lula, ao sufixo, denominando por consequência os ideais desses candidatos como

CHISHMAN, R. L. O., SANTOS, A. N., MARTINS, P. 0 fenômeno da neologia lexical nas eleicõos de 2018 
Linha D’Água (Online), São Paulo, v. 33, n. 1, p. 129-149, jan.-abr. 2020

diferentes doutrinas. O último ocasionou a nominalização do adjetivo coitado, fazendo assim referência ao ato de vitimização.

(x) ISTA - O sufixo -ista remete à ideia de "partidários ou sectários de doutrinas ou sistemas" (CUNHA; CINTRA, 1985, p. 70). Esse sufixo foi o mais produtivo em nossa pesquisa, correspondente a $27 \%$ do valor do gráfico. Tal aspecto vai ao encontro das conclusões de Alves (1990) a respeito do uso pervasivo de tal sufixo em formações neológicas, geralmente designando pessoas ou grupos que aderem a certos movimentos sociopolíticos. Especificamente neste estudo, foram seis os casos em que -ista apareceu: amoedista, bolsonarista, cirista, pesselista, psolista e ursalista, sendo que, nos três primeiros casos, foi adicionado a substantivos próprios (Amoêdo, Bolsonaro, Ciro) e nos três últimos às siglas PSL (Partido Social Liberal), PSOL (Partido Socialismo e Liberdade) e URSAL (União das Repúblicas Socialistas da América Latina). Em todos os casos, os neologismos foram utilizados com o intuito de indicar pessoa que segue, aprova, compactua com a ideologia de candidatos ou partidos políticos.

(xi) LÂNDIA - Esse sufixo faz referência à terra, território, cidade ou país característico de um grupo. Apenas um caso foi levantado a partir dos dados coletados, sendo ele a palavra petelândia, construída a partir da junção da sigla PT (Partido dos Trabalhadores) ao sufixo. -Lândia pode também ser utilizado para formação de palavras com sentido pejorativo, uma vez que pode se referir de maneira irônica aos locais em que determinado fator ou grupo específico exerce maior influência. É esse o caso do termo petelândia, usado como referência às regiões com maior número de adeptos do Partido dos Trabalhadores, bem como ao seu grupo de eleitores.

\section{Conversiva ou imprópria}

No caso do glossário, apenas um termo foi alocado nessa subcategoria: coiso, masculino de coisa. Esse caso é bastante peculiar, uma vez que se trata da criação de uma marca masculina. Destaca-se, contudo, tratar-se de um caso de difícil classificação, haja vista que uma das características desse tipo de derivação é a não introdução de qualquer distinção formal entre base e derivado. Poderíamos também ter 
Linha D’Água (Online), São Paulo, v. 33, n. 1, p. 129-149, jan.-abr. 2020

optado por considerar um caso de derivação regressiva, já que o substantivo coiso deriva do verbo coisar. Tal escolha, no entanto, seria adequada se tivéssemos um derivado indicando um processo de nominalização deverbal, como em fuga como derivado de fugir.

Não foram encontrados casos de derivação regressiva e parassintética.

\subsection{Composição}

A composição morfológica, ou ainda composição erudita segundo a gramática tradicional, ocorre a partir da construção de palavras com utilização de unidades não autônomas, também chamadas de unidades infralexicais. São exemplos dessas unidades "as raízes gregas e latinas já adaptadas ao sistema fonológico do Português” (CORREIA; ALMEIDA, 2012, p. 52).

Em nosso estudo, foram obtidos dois neologismos oriundos desse processo: cirocracia e neoantipetismo. Em ambas as palavras, há a presença de um radical grego, sendo que -cracia, na primeira palavra, remete a poder, enquanto -neo, na segunda, quer dizer novo (CUNHA; CINTRA. 1985, p. 82-83).

O processo de composição por justaposição ocorre quando há a junção de duas palavras, sem que os aspectos fonológicos dos constituintes sejam alterados. $\mathrm{O}$ único termo a se enquadrar nesse subgrupo foi cirominion, em que se unem o substantivo próprio Ciro e o termo estrangeiro minion.

Esse neologismo possui características peculiares, uma vez que a junção do termo brasileiro ao termo inglês o coloca em posição de hibridismo. Porém, devido à forma como a integridade fonológica das palavras foi mantida na criação do neologismo, optou-se por colocá-lo nesse subtipo.

Há ainda a composição por aglutinação, caracterizada pela perda de segmentos no momento de formação da nova palavra. Dentre os casos de composição, a aglutinação foi a subcategoria mais produtiva: cerca de três do total de oito termos compostos foram aqui organizados. São eles: comunolarápio, em que comuno (comunista) se junta a larápio, e lulopetismo, em que ocorre o acréscimo de Lula a petismo.

Há ainda outro caso, esse diferenciado: trata-se de lavazap, neologismo formado a partir de aglutinação, mas que merece destaque devido ao fato de que zap 
Linha D’Água (Online), São Paulo, v. 33, n. 1, p. 129-149, jan.-abr. 2020

é, na verdade, forma truncada de WhatsApp. Considerando-se então esses dois pontos, preferiu-se mantê-lo nesse subgrupo.

\subsection{Processos Deformacionais}

Dentre todos os processos de inovação lexical, os neologismos formados por intermédio desse grupo se sobressaíram, estabelecendo essa categoria como a segunda mais produtiva (23 unidades lexicais) e também como a detentora da segunda maior porcentagem do gráfico (28\%). Incluem-se nessa categoria amálgamas, siglas, acrônimos e truncações.

Quando partes de palavras diferentes se unem e formam uma nova unidade lexical, tem-se uma amálgama. Dentre as 21 unidades lexicais dessa categoria, 20 pertencem a esse subtipo e foram criadas tanto pela junção substantivo + substantivo, quanto por substantivo + adjetivo e vice-versa.

São essas as unidades lexicais: arregonaro (arregão e Bolsonaro); bolnossauro (Bolsonaro e dinossauro); bolsochato (Bolsonaro e chato); bolsolão (Bolsonaro e mensalão); bolsomito (Bolsonaro e mito); bonossauro, variante de bolnossauro; bolsonazi, (Bolsonaro e nazi); bozonaro (bozo e Bolsonaro); brasilha (Brasilia e ilha); brazuela (Brasil e Venezuela); cagonaro (cagão e Bolsonaro); falsibaddad (falso e Haddad); frauddad (fraude e Haddad); hamor (Haddad e amor); leitonaro (Eduardo Leite e Bolsonaro); luladrão, formado por Lula + ladrão; lulhaddad, Lula + Haddad; maldaddad (mal e Haddad); manudaddad (Manuela e Haddad); e tranquiliddad (tranquilidade e Haddad).

Vale frisar que as amálgamas, também conhecidas como blends ou mots-valise, são indicadoras da criatividade linguística e da própria imaginação de seus criadores, aspecto evidente nos dados de nosso estudo.

As siglas se formam a partir da junção das iniciais de um sintagma, gerando assim uma unidade que possui denominação própria (CORREIA; ALMEIDA. 2012, p. 58). ABL, Academia Brasileira de Letras, é um exemplo desse processo. Já os acrônimos são construídos não somente por meio de letras, mas também de sílabas, como acontece em Abralin (Associação Brasileira de Linguística).

Encontramos, em nossa coleta, três casos de acrônimos, sendo eles: alcirina, cirina e lúcifer. $\mathrm{O}$ primeiro caso é formado com os substantivos próprios Alckmin, 
Linha D’Água (Online), São Paulo, v. 33, n. 1, p. 129-149, jan.-abr. 2020

Ciro e Marina; o segundo, com os substantivos Ciro e Marina; e o terceiro, com os substantivos Lula, Ciro e Fernando, ainda fazendo referência à Bíblia Cristã.

Não foram identificados neologismos formados por meio dos processos de truncação.

\subsection{Lexicalização de estruturas}

No que diz respeito aos casos de lexicalização, foram encontradas nove unidades lexicais que se encaixam nessa subcategoria; são elas: elenão, elenon, elesim, jair embora, jair se acostumando, ptnão, alckmin dead, virar voto e farsa jato. Muitos desses neologismos apresentam peculiaridades, como é o caso de alckmin dead, referência à série The Walking Dead e, portanto, gerado na relação de um substantivo próprio a um termo estrangeiro.

\section{Extensão Semântica}

Quando palavras já existentes na língua adquirem novos significados, tem-se a inovação lexical através da extensão semântica. Dos 73 neologismos, sete se formaram a partir desse processo: desidratar, com o novo sentido de enfraquecer; doce de Pelotas, referência a Eduardo Leite, candidato ao governo do estado e originário da cidade de Pelotas, que é conhecida como produtora de doces; grostoli de Caxias, referência a José Ivo Sartori, candidato ao governo do estado e originário da cidade de Caxias, e ao doce tradicional da região; poste, substantivo usado para falar de Haddad; rihappy, adjetivo utilizado pejorativamente com relação à esquerda; mito, termo usado pelos admiradores de Bolsonaro; e Joesley Safadão, junção de Wesley e Joesley Batista, usado para indicar os atos corruptos realizados pelo empresário.

\section{Empréstimos e Hibridismos}

Apenas um empréstimo foi apresentado no glossário: fake nerws, neologismo de destaque durante as eleições devido ao grande número de notícias falsas divulgadas nas mídias sociais, o que ocasionou, por vezes, confusão por parte dos eleitores. 
Linha D’Água (Online), São Paulo, v. 33, n. 1, p. 129-149, jan.-abr. 2020

Quando palavras de línguas diferentes se unem no processo de inovação lexical, o termo resultante é chamado de hibridismo. No glossário, apareceram quatro casos desse tipo: bolsofake, bolsominion, esfakeado e réuboy. Os dois primeiros casos são formados a partir da união de Bolsonaro a fake e minion, ambos termos da língua inglesa. No terceiro caso, fake aparece no meio da palavra original esfaqueado, mudando assim seu sentido. No último caso, têm-se réu + boy, termo inglês.

Alguns desses casos podem vir a parecer pertencentes a outros subtipos. É o que acontece com bolsominion, que também aparenta ser um caso de amálgama. $\mathrm{O}$ mesmo ocorre com bolsofake e esfakeado.

\section{Considerações finais}

Em nosso trabalho, buscamos estudar a criação de neologismos que remetem ao domínio político, mais especificamente os neologismos empregados no período de campanha e eleições brasileiras de 2018. Priorizando o critério lexicográfico, elencamos 73 neologismos, os quais vieram a fazer parte do Glossário Neopolitiquês (CHISHMAN, 2018), recurso construído como atividade pedagógica realizada na disciplina de Fundamentos de Morfologia em curso no mesmo ano.

Em nossa análise, observamos a alta incidência de neologismos criados por meio de derivação sufixal, equivalendo a $33 \%$ do total, assim como de processos deformacionais, correspondendo a 28\%, em especial casos de amálgama, com 21 unidades lexicais. Como fechamento de nossa reflexão, cabe retomar a divisão em neologia denominativa e neologia estilística apresentada por Correia e Almeida (2012, p. 18). Os casos de derivação sufixal, que somaram 21 dos 22 casos de derivação, servem para corroborar ser a sufixação o mecanismo mais rico e diversificado da língua portuguesa. É nessa classe que encontramos os casos de neologia denominativa, ainda que em sua maioria restritos a nomes de políticos ou a partidos, e não a objetos ou conceitos. Ao encontro dos resultados encontrados por Alves (1990), destacam-se o sufixo -ista, formador de adjetivos com valor de adepto a e partidário de, e o sufixo -ismo, formador de nomes com o sentido de adepto, partidário. Em ambos os casos, os sufixos estão associados a antroponímias, como em cirista, amoedista, bolsonarista, ou como em cirismo, daciolismo, lulismo. 
Linha D’Água (Online), São Paulo, v. 33, n. 1, p. 129-149, jan.-abr. 2020

Já os neologismos criados por processos deformacionais se destacam por indicarem, em sua grande maioria, casos de neologia estilística, evidenciando a intenção dos usuários em criar tais termos como forma de expressar sua opinião ou sua repulsa a um ou outro candidato. É o que expressam palavras criadas por mecanismos de amálgama, como arregonaro, bolsomito, bolnossauro e malddad, em que se evidencia o sentido pejorativo ou de ofensa.

Por fim, ainda que se tenha ciência de que fazer o levantamento de neologismos de um período específico não se trata de tarefa simples, principalmente por ter sido desenvolvido em sala de aula, foi possível ratificar a ideia de que o léxico tem sim o papel de materializar a realidade. Os neologismos estudados, com certeza, servirão como memória desse singular evento da história política do país, que foram as eleições federais de 2018.

\section{Referências}

ALVES, I. M. Neologismo: criação lexical. São Paulo: Editora Ática, 1990.

ALVES, I. M. O prefixo hiper- em um corpus jornalístico do português brasileiro. Matraga, Rio de Janeiro, v. 18, p. 129-142, jan./jun. 2011.

BOULANGER, J. Néologie et terminologie. Neólogie en Marche, Montreal, v. 4, p. 5-128, 1979.

CARVALHO, N. A criação neológica. Revista Trama, Marechal Cândido Rondon, v. 2, n. 4, p. 191-203, jul./dez. 2006.

CABRÉ, M. T. C. La clasificación de neologismos: una tarea compleja. Alfa, São Paulo, v. 50, n. 2, p. 229-250, jul./dez. 2003.

CHISHMAN, R. (Org.) Glossário Neopolitiquês. São Leopoldo: Unisinos, 2018. Disponível em: https://gneo2018.wixsite.com/gneo2018. Acesso em: 19 out. 2019.

CORREIA, M., ALMEIDA, G. Neologia em português. São Paulo: Parábola Editorial, 2012. 
Linha D’Água (Online), São Paulo, v. 33, n. 1, p. 129-149, jan.-abr. 2020

CUNHA, C.; CINTRA, L. Nova gramática do português contemporâneo. Rio de Janeiro: Nova Fronteira, 1985.

DICIONÁRIO AULETE. São Paulo: Lexicon Editora Digital, 2015. Disponível em: http:// www.aulete.com.br. Acesso em: 19 out. 2019.

GUILBERT, L. La créativité lexical. Paris: Larousse, 1975.

HOUAISS, A. Dicionário eletrônico Houaiss da Lingua Portuguesa. Rio de Janeiro: Objetiva, 2007.

MICHAELIS: Dicionário Brasileiro da Língua Portuguesa. São Paulo: Editora Melhoramentos, 2015. Disponível em: https://michaelis.uol.com.br. Acesso em: 19 out. 2019.

RAJAGOPALAN, K. Por uma linguística crítica: linguagem, identidade e questão ética. São Paulo: Parábola Editorial, 2003.

REY, A. Néologisme: un pseudo-concept? Cabiers de Lexicologie, Paris, n. 28, p. 3-17, 1976.

SABLAYROLLES, J. F. Néologismes: une typologie des typologies. Cabiers du CIEL 19961997, Paris, p. 11-48, 1996.

SANDMANN, A. J. Formação de palavras no português contemporâneo brasileiro. Curitiba: Scentia \& Labor, 1985.

SANDMANN, A. J. Morfologia geral. São Paulo: Contexto, 1989.

OBSERVATORI DE NEOLOGÍA. Metodología del trabajo en neología: criterios, materiales y procesos. Barcelona: IULA, 2004.

Recebido: 20/10/2019.

Aprovado: 24/02/2019.

CHISHMAN, R. L. O., SANTOS, A. N., MARTINS, P. 0 fenômeno da neologia lexical nas eleicõos de 2018 